\title{
STUDY OF IMPACT OF POSITIONING THE OBJECT SURVEY AND SELECTION OF WORK POSITION ON THE BURDEN OF WORK
}

\author{
Ivan Lazarov, Krasimir Ivanov, Rumyana Tasheva, Gentcho Genev \\ Faculty of Technics and Technologies, Trakia University, Bulgaria \\ 38 Graf Ignatiev str., 8600 Yambol, Bulgaria \\ mobile: +359 878 115586, e-mail: isl51@abv.bg
}

\begin{abstract}
The report describes the importance of the right choice of working position and positioning of the object to the operator when performing machining and assembling operations.

The influence of the system of external forces, arising from manual handling of power tools, burden of the work. Their counterproductive force has an applied point on the human palm.

From there, the power is transmitted and affect each of the elements (hand, body, foot, base) of the power chain - the system of muscles, bones, and joints of the human.
\end{abstract}

Keywords: positioning, work position, burden of the work.

\section{INTRODUCTION}

When performing the plumbing-assembling technological processes, used in the maintenance and repair of energy machines and equipment, hand-held power tools are often used to facilitate the rapid and qualitative execution of assignments. .

According to the normative documents, the necessary conditions for ensuring the safety and health of the workers, in particular their long-term working time and protection from fatigue must be created in the organization of the work activity. Therefore, optimal working and rest periods for workers should be introduced in enterprises, according to the specifics of their work, as well as the characteristics and elements of their workplace.

The purpose of this study is to analyze the influence of the system of external forces, arising in the manual operation of a power tool on the weight of labor, as their coercive force is applied to the human hand, and from there it transmits and influences each the elements (hand, body, leg, base) of the power chain - the system of muscles, bones and joints of man.

\section{POWER ANALYSIS FOR HANDLING ELECTRICAL TOOLS}

\subsection{Plan of the acting forces on handling electrical tools}

The plan of the acting forces on handling electrical tools is presented in Figure 1.

\subsection{Distribution of forces according to axial force direction $F_{O C}$ during drilling and short characterization of the working posture}

Depending on the positional distribution of the two connecting external forces (axial force $F_{\mathrm{OC}}$ at drilling and the weight $\mathrm{G}$ of the power tool) relative to the direction $n-n$, which is normal to the machined (face) surface of the object of action, the magnitude of the $F_{\text {PAE }}$ equivalent force that the worker has to apply during processing is obtained $[5,6]$. 


\section{IRTIIL}

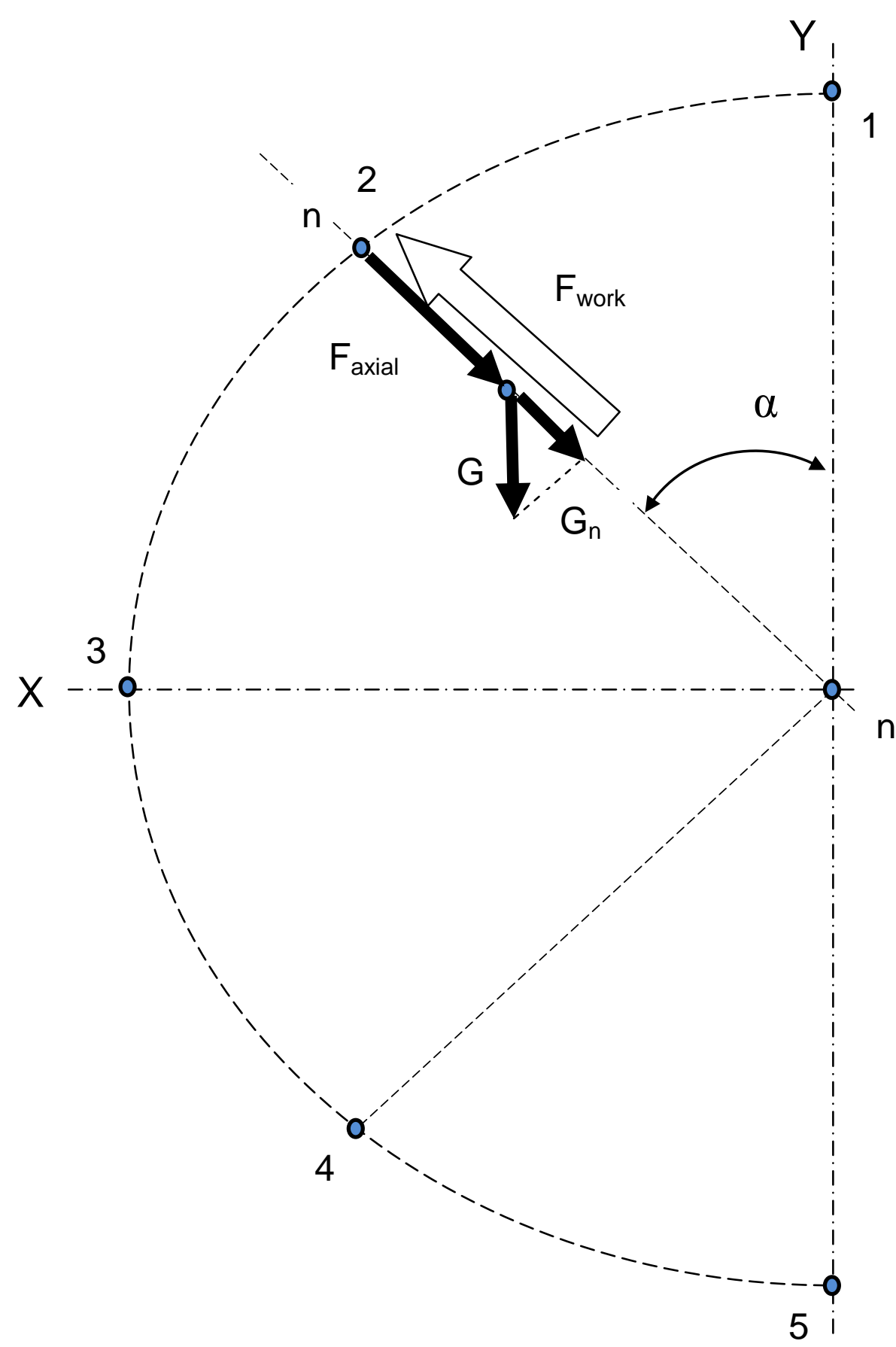

Figure 1. Plan of the acting forces on handling electrical tools (position 2) $F_{\text {axial }}$ - axial force when drilling, $G$ - weight of the power tool, $G_{n}$ - projection of $G$ on the $n-n$ direction, $F_{\text {work }}-$ force applied by the operator's hand when drilling, $\alpha-$ angle of inclination of the tool axis with respect to the vertical axis $Y$ 


\section{IRTIIE}

Ipplied Researriches in Technics, Technologies and Bducation Journal of the Faculty of Technics and Technologies, Trakia University https://sites.google.com/a/trakia-uni.bg/artte/

Position $1\left(\alpha=0^{\circ}\right)$
Most unfavorable working position (ceiling performance) due to:
(1.1) Positioning of the object at a higher level than the working shoulder and perpendicular
to the axis of the body, causing uncomfortable placement of the body - with a backward
inclined head and arms raised forward and upward;
(1.2) Maximum force response $F_{\text {work }}$ - as the sum of the axle force $F_{\text {axial }}$ and the weight $G$ of
the instrument;
(1.3) Need to take precautions against the risk of dust, chips and other mechanical elements
from drilling in the eyes and/ or face of the worker.

Position $2\left(\alpha=45^{\circ}\right)$
Unfavorable working position due to:
(2.1) Similar to (1.1);
(2.2) Significant forceful opposition $F_{\text {work }}-$ as the sum of axial force $F_{\text {axial }}$ and the projection of
the weight $G_{n}$ of the tool on the axis $n-n ;$
(2.3) Need to take precautions against the risk of dust, chips, etc. mechanical elements of
the drilling in the eyes and/ or face of the worker.




\section{ARTIIE Ipplied Resererr'ches in Technics, Technologies ind Bduration Journal of the Faculty of Technics and Technologies, Trakia University https://sites.google.com/a/trakia-uni.bg/artte/}

Position $3\left(\alpha=90^{\circ}\right)$
Favorable working position due to:
(3.1) Ability to occupy a steady positioning of the body and hands in a straight posture;
(3.2) Ability to more evenly distribute the applied force effect $F_{\text {work }}$ between the hands and
body of the worker;
(3.3) Less force response $F_{\text {work }}$ only obtained by the axial force $F_{\text {axial }}$ because the tool's
weight $\mathrm{G}$ is in a direction perpendicular to the axis $\mathrm{n}$ - $\mathrm{n}$.

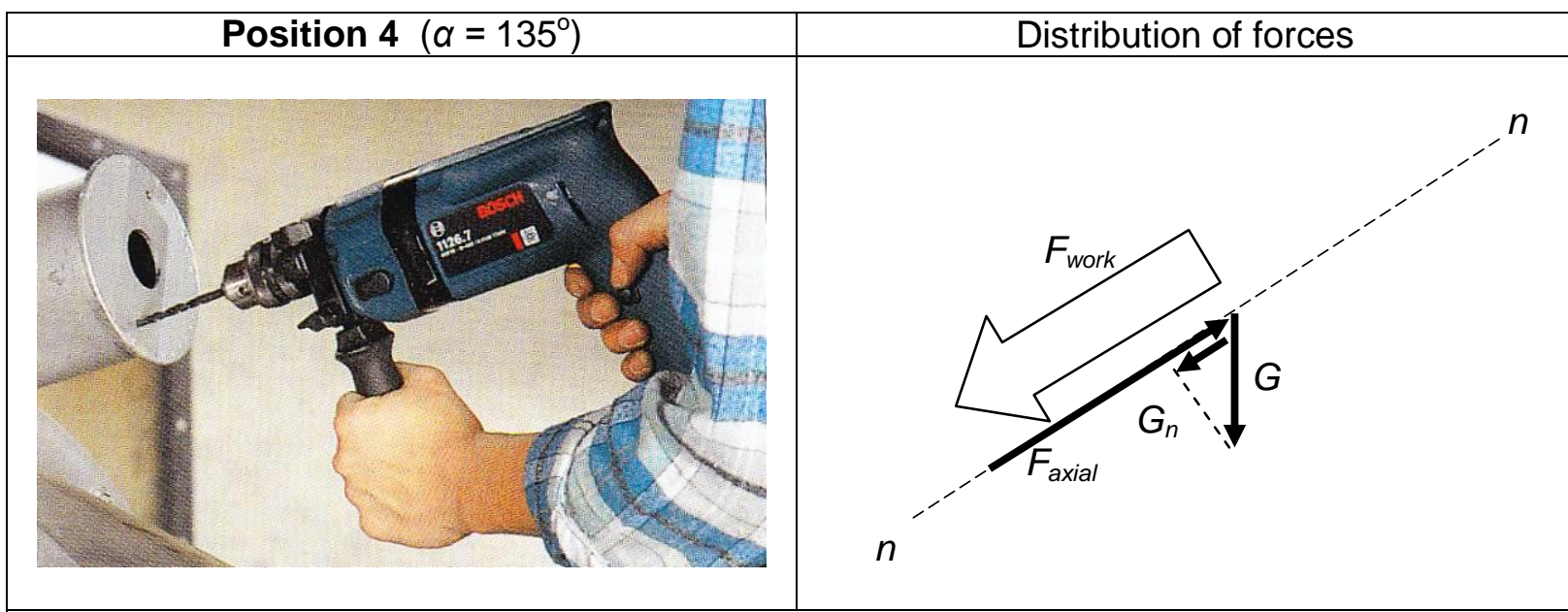

Favorable working position due to:

(4.1) As with (3.1), but it necessitates some bending of the body forward at an angle;

(4.2) As with (3.2);

(4.3) Quite a less powerful $F_{\text {work }}$ response, obtained as a difference from the axial force $F_{\text {axial }}$ and the projection $G_{n}$ on the weight $G$ on the n-n axis. 


Position $5\left(\alpha=180^{\circ}\right)$
The most favorable working position due to:
(5.1) As with (3.1), but it forces a certain bending of the body forward;
(5.2) As with (3.2);
(5.3) Minimum force response $F_{\text {work, }}$ obtained as a difference from the axle force $F_{\text {axial }}$ and the
weight G on the axis $\mathrm{n}$ - $\mathrm{n}$;
(5.4) When positioning the subject at a significantly lower level, it is necessary to occupy a
heavier forward position of the body causing a risk of diseases in the waist area.

\subsection{Determination of axial force $F_{\text {axial }}$ when drilling and the weight $G$ of the tool}

Axial force $F_{a x i a l}$ when drilling is determined by the following formula [1,2]:

$$
F_{\text {axial }}=9,81 \cdot C_{F} \cdot D_{F}^{q} \cdot S_{F}^{Y} \cdot K_{F}
$$

where $C_{F}$ is a coefficient that depends on the material being processed; $C_{F}=68$ for steel 45 $\mathrm{Cbc} \sigma_{\mathrm{B}}=60.10^{7} \mathrm{~Pa}$ и $\mathrm{HB}=156-207$;

$\mathrm{D}=6 \mathrm{~mm}-$ diameter of the drilled hole;

$\mathrm{S}=0,06 \mathrm{~mm} / \mathrm{r}-$ submission the tool when drilling;

$\mathrm{q}_{\mathrm{F}}=1$ - exponent - for steel 45 ;

$\mathrm{Y}_{\mathrm{F}}=0,7$ - exponent;

$\mathrm{n}_{\mathrm{F}}=0,75$ - exponent;

$\mathrm{K}_{\mathrm{F}}-$ coefficient.

$$
\begin{gathered}
K_{F}=\left(\sigma_{B} / 75\right)^{n} F \\
K_{F}=(60 / 75)^{0,75}=0,846 .
\end{gathered}
$$$$
F_{\text {axial }}=9,81 \cdot 68 \cdot 6 \cdot 0,139 \cdot 0,846=470,7 \mathrm{~N}=47,0 \mathrm{~kg}
$$

$\mathrm{G}=3,3 \mathrm{~kg}$ - weight of the power tool - on an electrically-powered hand-held model $\mathrm{BZ}$ $16 \mathrm{D}$ with power $650 \mathrm{~W}$, producing a company ELTOS- Lovech $[3,4]$. 


\subsection{Power Distribution of $F_{\text {work }}$ according to the positioning angle $\alpha$}

The magnitude of the power $F_{\text {work }}$ is determined by the magnitude of the positioning angle $\alpha$ of the formula (3):

$$
F_{\text {work }}=\mathrm{F}_{\text {axial }} \pm G_{n}=F_{\mathrm{OC}} \pm G \cdot \cos \alpha
$$

Table 1. Size of power $F_{\text {work }}$ according to the positioning angle $\alpha$

\begin{tabular}{|c|c|c|c|c|c|c|c|c|c|}
\hline $\boldsymbol{\alpha}$ & $0^{\circ}$ & $30^{\circ}$ & $45^{\circ}$ & $60^{\circ}$ & $90^{\circ}$ & $120^{\circ}$ & $135^{\circ}$ & $150^{\circ}$ & $180^{\circ}$ \\
\hline $\mathbf{F}_{\text {axial }}, \mathrm{kg}$ & 47,0 & 47,0 & 47,0 & 47,0 & 47,0 & 47,0 & 47,0 & 47,0 & 47,0 \\
\hline $\mathbf{G}_{\mathbf{n}}, \mathrm{kg}$ & $+3,300$ & $+2,858$ & $+2,333$ & $+1,650$ & 0,00 & $-1,650$ & $-2,333$ & $-2,858$ & $-3,300$ \\
\hline $\mathbf{F}_{\text {work }}, \mathrm{kg}$ & 50,300 & 49,858 & 49,333 & 48,650 & 47,000 & 45,350 & 44,666 & 44,142 & 43,700 \\
\hline
\end{tabular}

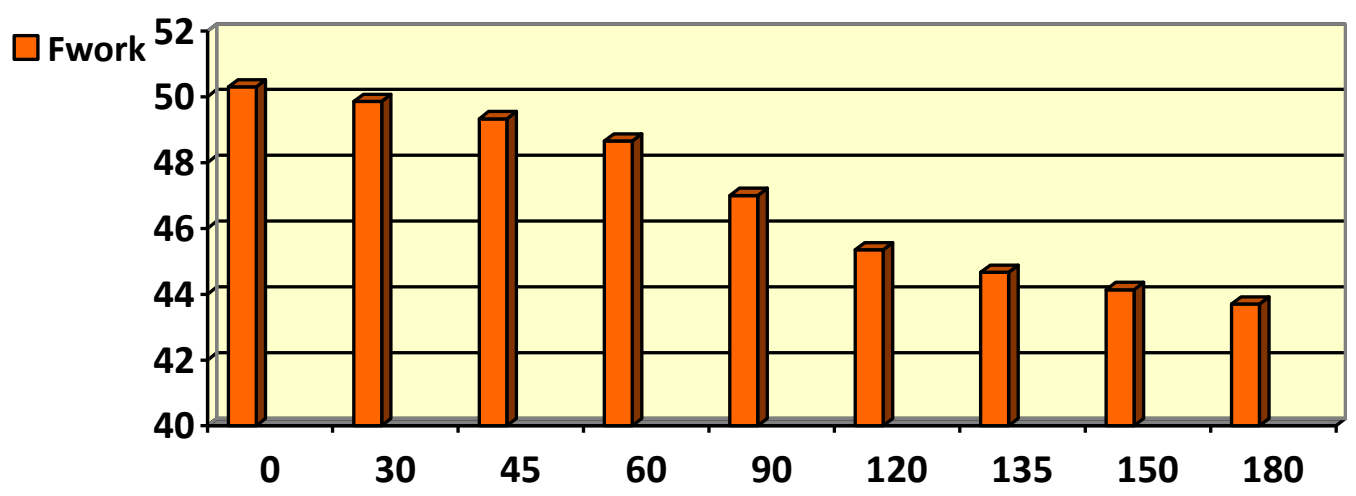

\subsection{Relative increase in the power $\Delta F_{\text {work }}$}

$$
\Delta F_{\text {work }}=\left(F_{\max }-F_{\min }\right) / F_{\min } \cdot 100 \%
$$

where $F_{\max }$ is the maximum value of the force $F_{\text {work }} ; F_{\max }=50,3 \mathrm{~kg}$ при $\boldsymbol{\alpha}=0^{\circ}$; $F_{\min }$ - the minimum value of the force $F_{\text {work }} ; F_{\min }=43,7 \mathrm{~kg}$ при $\alpha=180^{\circ}$.

$$
\Delta F_{\text {work }}=(50,3-43,7) / 43,7.100=15,1 \%
$$

As a result of the conducted study, the following conclusions are necessary:

1. With increasing the value of the a angle from $0^{\circ}$ to $180^{\circ}$, the resultant force $F_{\text {work }}$ decreases from its maximum to the minimum due to the decrease in the size of the component $G_{n}$ of the weight of the tool $G$ along the $n-n$ axis and the change in the axial force direction $F_{\text {axial. }}$.

2. Changing the value of angle $\alpha$ from $180^{\circ}$ to $0^{\circ}$ requires an employee to get an increasingly disadvantageous working position. This contributes to the emergence of additional technogenic risk factors requiring additional preventive measures.

3. The significant relative increase (by $15.1 \%$ ) of the power $F_{\text {work, }}$ applied by the drilling operation due to the change in angle $\alpha$, contributes to an increase in the severity of work and a reduction in working capacity, especially when performing multiple operations. 


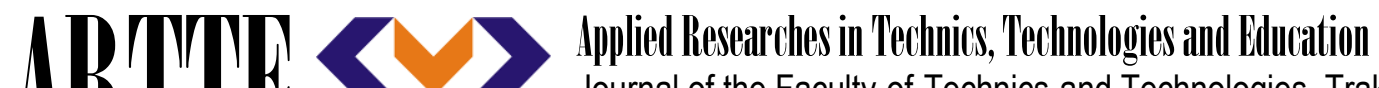 Journal of the Faculty of Technics and Technologies, Trakia University https://sites.google.com/a/trakia-uni.bg/artte/}

\section{CONCLUSIONS}

With the present work, the authors propose a new approach to risk prevention for the safety and health of workers by force analysis when performing a drilling-assembling drilling operation. This approach is achieved:

- Combination of the process of technological design of plumbing-assembling operations with the process of ensuring safe and healthy working conditions in the working environment;

- Optimizing the organization of work through:

- Presentation of preventive measures for correct and safe positioning of the system "worker - subject of influence";

- Introduction of safe working and rest periods, according to the specifics of the workplace, the elements of the technological system and the nature of the activity.

\section{REFERENCES}

[1] Baranovsky, Yu.V. Cutting modes of metals. M., NIITAP, Mechanical Engineering, 1972, p.124-126 (in Russian).

[2] Gatev, G. et al. Guide Course Design Manufacturing Technologies. S., Technika, 1980, pp. 114-116 (in Bulgarian).

[3] Company Prospectus ELTOS, 2000.

[4] Company Prospectus BOSCH, 2012.

[5] Cartoon conspiracy gif GIPHY, https://giphy.com/gifs/cartoon-conspiracymQCjPk19rkW2Y (available on 01.10.2017).

[6] Work-related Musculoskeletal Disorders (WMSDs) - Risk Factors, https://www.ccohs.ca/oshanswers/ergonomics/risk.html (available on 12.10.2017). 